\title{
Energy and Heat for Medium-sized Cities in a Temperate Climate From a Small Nuclear Reactor and Solar Panels
}

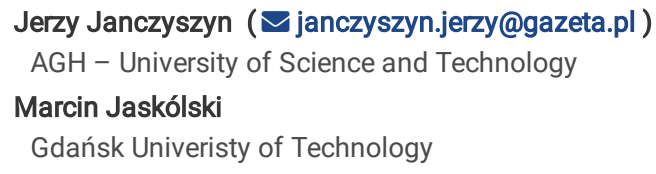




\section{Abstract}

The article discusses the possibilities of using a system consisting of small nuclear reactors, solar collectors and a heat accumulator in future carbon-free conditions. Kraków (Poland) was chosen as an example of a city supplied with electricity, and heat from the discussed system. The demand for electricity and heat was estimated, possible technical solutions were proposed in an approximate manner and monthly balances of electricity and heat were calculated. It was found impossible to meet the energy needs by using only renewable sources in specific conditions of moderate and season-dependent intensity values of sun and wind. The only and efficient option that is able to cover the city's demand for electricity and heat is a nuclear power plant, consisting, for example, of NuScale nuclear units in combination with solar collectors and a properly selected heat accumulator. Fifty $\mathrm{MW}_{\mathrm{el}}$ reactors were considered, but a new version of the NuScale modular reactor with a modular capacity of $77 \mathrm{MW}_{\mathrm{el}}$ is also briefly shown.

\section{Introduction}

In addition to fossil fuel-based facilities, nuclear power plants (NPPs), wind turbines (WTs), photovoltaic (PV) systems and solar panels (SP-) are important energy technology options available. In connection with the adopted long-term vision of the development of energy systems in the European Union, we ask which of these solutions are possible to apply in the future in Poland in view of the withdrawal from fossil fuel use by 2050 . In Polish conditions, the energy potential of hydroelectric power plants is exhausted and geothermal energy resources are insufficient to fill the gap that will arise after shutting down coalfired power plants. Solar energy, despite its environmental advantages and declining PV prices, has limited possibilities to replace fossil fuel-based technologies, mainly due to the low peak power utilization factor, high variability of power generation, depending on insolation and temperature, and maladjustment to simultaneous coverage of the electricity and heat needs in concentrated form, i.e. mainly for large cities and industrial plants. Thus, NPPs and WTs remain potentially available options, but the latter also show a high dependence on weather conditions, i.e. wind speed, the value and stability of which depend on the location. Installing a large number of WTs will require the simultaneous construction of intervention sources and energy storage, with very limited current possibilities of accumulating large amounts of energy. Nevertheless, the Energy Policy of Poland until 2040 supports investments in offshore WTs, at the same time pointing to the need to quickly make decisions on the implementation of nuclear energy. In the field of cogeneration systems, the number of technological options that can be installed is even more limited. Steam and gas combined cycle units, characterized by high energy efficiency and relatively low specific investment expenditure, will have to bear high costs related to the purchase of gaseous fuel and $\mathrm{CO}_{2}$ emission allowances. On the other hand, incinerators where the fuel may be selected waste (RDF - refuse derived fuel), the price of which is negative (the incinerator receives a payment for waste disposal), need to meet stringent requirements to comply with best available techniques (BAT) conclusions, which discourages the investment. Biomass heat and power plants can use the renewable energy source (RES) auction mechanism, but they must ensure the supply of fuel in the right amount and at a price that would guarantee the profitability of the project. All these options are and will be considered and are actually implemented in selected Polish cities. However, the aforementioned limitations result in the need to look for zero-emission options with high power density, as well as low fuel costs. Systems with small and medium power reactors (SMRs) are such an option. In Poland, interest in such a technology has already been shown by Synthos Green Energy, which considers the installation of a small-size boiling water reactor (BWR) with a modular structure (this time SMR may also represent a small modular reactor). This reactor is BWRX-300 and it is offered by GE Hitachi.

In this article, we consider a system consisting of a small nuclear reactor as well as solar collectors and heat accumulators. The proposed cogeneration system could supply cities - large (on the Polish scale) or medium (on the European scale) - with electricity and heat, with the possibility of adapting it to process heat (process steam). The considerations will be presented in the example of Krakow, Poland.

\section{Demand For Power And Energy}

To design a system that meets the demand for electricity and heat in a given city, the annual energy demand and its distribution over time as well as the peak demand for power should be determined. The total electricity and heat demand and power loads were taken from the municipal energy supply plan [1]. The respective expected values for Kraków (740,000 inhabitants) in 2020 are presented in Table 1. The authors do not have data on the monthly distribution of electricity and heat demand in Kraków. Therefore, for the purposes of this analysis, they were properly estimated on the basis of data on loads in the national electricity system [2] and heat demand characteristics for Prague (Czech Republic) [3], which is located in climatic conditions similar to Kraków. In both cases, the characteristics were obtained after scaling in accordance with extreme values. The results of such approximations are presented in Fig. 1 for electric power and in Fig. 2 for thermal power.

Table 1

Projected values characteristic of the Krakow energy system in 2030 [1]

\begin{tabular}{|lllll|}
\hline \multicolumn{3}{|l|}{ Total power required } & \multicolumn{4}{l|}{ Annual energy } \\
\hline electric & heat & electric & heat & \\
\hline MW & MW & TWh/a & TWh/a & TJ/a \\
\hline 616 & 1600 & 2,85 & 2,78 & 10000 \\
\hline
\end{tabular}

Figure 1 Characteristic monthly values of electricity demand in Kraków (based on data from October 1, 2018 to September 30, 2019)

\section{Considered Options For Supplying Kraków With Electricity And Heat}

Below, we consider possible energy sources and corresponding technologies that can meet the demand for energy carriers if fossil fuels are excluded. 


\subsection{Electricity}

Solar power systems are the first option considered. If the photovoltaic installation was to operate independently and not to cooperate with the NPP, it would have to store electricity on summer days to ensure maximum power, i.e. $500 \mathrm{MW}$ during winter days at full load, i.e. during dark hours. To day, there has been no practical solution for storing so much electricity for several months. Tesla's most powerful battery can run at $250 \mathrm{MW}$ but is only able to store up to $1 \mathrm{GWh}$ of energy, occupying an area of 120 ha. In addition, in a location with low solar radiation, a large surface area for solar modules would be required. In Poland, the power plant with an installed capacity of $3.77 \mathrm{MW}$, in the Czernikowo commune (Kujawsko-Pomorskie Voivodeship), covers an area of 7.7 ha, of which $2.25 \mathrm{ha}$ is occupied by photovoltaic modules alone. It provides about $3500 \mathrm{MWh} / \mathrm{a}$ of electricity [4]. This gives an average surface power density of approx. 18 $\mathrm{MW} / \mathrm{km}^{2}$, while the measurements carried out by the University of Opole in 2011-2012 showed a value of 8-9 MW/km² [5].

In the calculations below, we optimistically assumed the efficiency of available photovoltaic cells to be $20 \%$. In December, it is necessary to produce approx. $390 \mathrm{GWh}$ of electricity for Krakow within a month, while the production from PV is only approx. $165 \mathrm{MWh} / \mathrm{km}^{2}$ per day, and at noon approx. $34 \mathrm{MWh} / \mathrm{km}{ }^{2}$ per hour. Then, the required area of the land for the modules would be approx. $75 \mathrm{~km}^{2}$. There are still two problems to be solved. First, approximately $8 \mathrm{GWh} /$ $\mathrm{d}$ of electricity would have to be stored for seven hours each day to meet the demand in December. Second, in the remaining time the electricity power generated during the June solar peak (at 12:00) would be approximately $7.5 \mathrm{GW}$, and the surplus energy produced in one day would be around $65 \mathrm{GWh} /$ day. This amount of electricity would have to be consumed daily for many days, which is practically impossible. Even conversion to heat or cold would use only a fraction of this amount due to the low demand for these energy carriers. Hydrogen production would require huge, rarely available natural underground reservoirs. Additionally, the overall efficiency of the electricity-hydrogen-electricity cycle is only about $50 \%$. Due to these circumstances, this option can be used exceptionally. It is worth adding that there is no information in the world on $100 \%$ coverage of energy demand by PV. On average, it is $20-30 \%$, and the highest values, for quite modest sizes of PV systems, are approx. 50\%. Practice shows that many technological problems are associated with a large share of renewable sources in the AC network, such as the difficulty of maintaining constant frequency and voltage values and the increase in electricity prices [6]. This shows that it is unrealistic to meet the electricity demand on the basis of solar energy alone. Taking into account the use of photovoltaics on the roofs of Krakow buildings, we can see that the data contained in the report [7] define the potential usable area of roofs at the level of approx. $9 \mathrm{~km}^{2}$ and the generated electricity at the level of approx. 1.8 TWh/a; however, this energy would be produced and used mainly in summer and would rather be unavailable in winter.

As a result, we need to consider another source of electricity based on fossil or nuclear fuels. Currently, solar farms can work, in medium and large cities, as an auxiliary source. They cannot be the only source of electricity. If we exclude coal or, more generally, fossil fuels, only NPP remains practically usable.

\subsection{Electricity and heat}

Two solutions can be considered to meet the city's electricity and heat needs:

\subsubsection{Nuclear heat and power plant}

Such a solution has already been analyzed in [8], listing three types of high-power nuclear reactors and taking into account the assumed seasonal changes in demand. The main assumption of the concept proposed in our work is the constant thermal power of a nuclear reactor. This capacity should cover the peak demand for electricity, i.e., $500 \mathrm{MW}$ in Kraków. The surplus - $P_{h h e l}^{N}$ can be used for heating. A reactor meeting these needs could be NuScale SMR (Small Modular Reactor) with all 12 modules (50 MW each) [9]. Then, the nominal power of the power plant would be $570 \mathrm{MW}$, which would allow the use of a significant part of the necessary heat during lower electricity demand - $P_{h h e l}^{Z}$.

$$
P_{h h e l}^{N}=570 M W-P_{h h e l}^{Z}
$$

1

In the calculations, we increased the power for heating by $20 \%$, taking into account the needs of municipal trade, i.e., heating of shops, cinemas, etc. The results presented in Fig. 1 show that the peak demand for electric power can reach $700 \mathrm{MWe}$, i.e. approximately 130 MWe above the nominal capacity of the twelve-block NuScale power plant. In such a situation, the power of the power plant could be supplemented for a short time from the national power system. At other times, there may even be a large excess of heat from the reactor. Some of this heat can be used in the form of high-temperature process steam (approx. $300^{\circ} \mathrm{C}$ ) directly from the steam generator. For lower temperatures, e.g., for district heating, the steam could come from the bleeds or from the passage between the individual stages or from the outlet of the turbine. This means that the system would function as a combined heat and power plant.

The distribution of the required thermal power over the year (Fig. 2) is less even then the electricity demand and shows large differences between winter and summer. Therefore, it is necessary to investigate whether the surplus from the reactor in individual months could fully cover the heat demand. This can be done by converting the monthly surplus of electric power of the reactor $-P_{e l}^{N}$ into the amount of heat and assuming the efficiency $\eta \cong 0,3$ (Eq. 2). The result is shown in Fig. 3.

$$
\Delta P_{\text {hheat }}^{R}=\frac{\left(570-P_{e l}^{Z}\right)}{\eta}
$$

\section{2}

In January, despite the low ambient temperature, quite strange excess heat can be noticed. However, the demand for electricity does not directly depend on temperature. The given values of demand are also indicative. We believe that a little bit of disagreement with reality should not significantly affect our main thought. As a result, we see that there is no surplus in February, but only a small surplus in December. 
Fig. 3 The assumed average monthly ambient temperature and power distribution of the excess heat available from the reactor - $\Delta P_{h e a t}^{R}$ $Q^{R}[G W h]=\Delta P_{\text {heat }}^{R}[\mathrm{MW}] t_{m}[\mathrm{~h}] / 1000$ (3)

$Q^{R}[G W h]$ - the amount of heat from the reactor that can be used in a month, $\Delta P_{h e a t}^{R}[\mathrm{MW}][\mathrm{MW}]$ - average potential excess heat output from the reactor in a given month, $t_{m}$ - number of hours in a given month.

The annual sum of excess heat - $\sum_{i=1}^{12} Q_{\text {heat }, i}^{R}$ reaches $3000 \mathrm{GWh}$, which only slightly exceeds the annual needs of Krakow. Considering the inevitable heat losses ine storage ( 5\% per month) and the amount needed in the winter months, it can be seen that one NuScale power plant is somewhat insufficient.

Therefore, we move on to the second option.

\subsubsection{Nuclear heat and power plant with a solar heating plant and heat storage}

Increasing the amount of necessary heat, as long as there is space for its storage, can be achieved by installing an appropriate surface of solar collectors. We assumed $3400 \mathrm{GWh}$ as the total annual heat demand (from the reactor and solar panels), taking into account the storage losses. After calculating the monthly heat shortages $\Delta Q^{B}$, it turned out that in April this value changed from negative to positive. The trial and error method was used to select the size of the surface of the solar collectors to ensure a positive value of the heat balance this month. It turned out that the required area is approx. $2.6 \mathrm{~km}^{2}$. The amount of heat obtained in this way is presented in Fig. 4. The graph allows us to assume that April is the first month with a net heat surplus. When the system is first launched in April, the first batch can be moved to storage. Over the following five months, further deliveries to the storage will be possible until September. From October, heat is taken from the storage until March inclusive. The graph in Fig. 5 shows the variation in time of the amount of energy in these flows and the level of heat in the storage. From the chart, we can determine the required maximum heat storage capacity at $\sim 1500 \mathrm{GWh}$ (in September) and the maximum heat flow to and from the warehouse, respectively, at $500 \mathrm{GWh} / \mathrm{month}$ in September and $-500 \mathrm{GWh} / \mathrm{month}$ in February.

We chose an underground hot water tank as the only type of storage that would keep heat from summer to winter and that would be able to efficiently store a large amount of energy $[10,11]$. It would occupy a considerable area, e.g. under a solar collector field. With a storage height of $\sim 10 \mathrm{~m}$, the area is $\sim 2.2 \mathrm{~km}{ }^{2}$. It is planned to be able to divide the storage into a low temperature section (HSTG) and a high temperature section (steam accumulators); see Fig. 6.

Important values related to the design and construction of the proposed combined heat and power plant are the maximum power values of heat exchange devices to and from storage. The monthly averages in both directions are approx. $600 \mathrm{MW}_{\mathrm{th}}$. While the winter consumption from storage should be fairly even, the reception of excess heat from the reactor would change during the day. This may require you to use more power temporarily. The assumption of the proposed solution was to operate the NuScale reactor with a constant thermal power, which would be divided between the turbine set and the heat storage and, if necessary, taken from the storage. The heat resources in the storage facilities would allow flexible daily supplies without changing the reactor load over time. A schematic diagram of the NuScale turbine system adapted to cogeneration is shown in Fig. 6 . Cogeneration can be achieved by taking steam from the turbine, i.e. from steam bleeds connected with medium- and low-pressure feed water heaters. Based on the power plant data published in [7], the thermal balance of a nuclear turbine was calculated in both condensation and cogeneration modes. As a result of the steam discharge from the turbine, the electric power of a single unit drops from $50.5 \mathrm{MW}_{\mathrm{e}}$ to $42.2 \mathrm{MW}_{\mathrm{e}}$, while the total gross electric power of the power plant measured at the generator terminals drops from $605.5 \mathrm{MW}_{\mathrm{e}}$ to $507.0 \mathrm{MW}_{\mathrm{e}}$. This reduction in electric power is observed at the peak thermal load of the nuclear unit, i.e. $50 \mathrm{MW}_{\mathrm{th}}$, which corresponds to the achievable thermal power of the CHP plant of $600 \mathrm{MW}_{\text {th }}$.

At peak heat load, the district heating system (DHS) water is heated to $120^{\circ} \mathrm{C}$, while the return water temperature from the DHS is $60^{\circ} \mathrm{C}$.

It was anticipated that the steam accumulators would act as a buffer for excess steam. They are charged when there is a surplus of electricity or heat in the relevant networks and discharged when any of these energy carriers are deficient. It is proposed to connect a nuclear power plant in parallel with a solar collector power plant in combination with low-temperature heat storage to match the heat supply with the demand. To conclude, we believe that the latter option is the most practical, economical and worth further analysis by a team of experts appointed for it.

\section{New Version Of Nuscale Reactor}

Recently, a new version of the NuScale modular reactor with a modular capacity of $77 \mathrm{MW}$ was proposed in the US. We checked how such a reactor would be suitable for Krakow. Our calculations, carried out similarly to those presented for the $50 \mathrm{MW}$ module, show that 10 modules with a capacity of $77 \mathrm{MW}$ each would cover the demand for electricity and heat throughout the year, according to the current needs assessments. Thanks to this solution, 9 modules can operate with full thermal power for 11 months, and one module can operate in January. In this version, the heat accumulator storing heat from summer to winter should have a heat capacity of $\sim 4300 \mathrm{TJ}\left(\sim 1.2 \mathrm{TWh}_{\mathrm{th}}\right)$ and an area of $\sim 1.8 \mathrm{~km}^{2}$. The heat transfer capacities to and from the storage would be +500 and $-600 \mathrm{MW}_{\text {th }}$, respectively. (Fig. 7).

\section{Summary And Conclusions}

It should be clearly stated that many of the figures quoted here are approximate, especially since we did not include the complete diagram of the electrical and thermal parts in the calculations. We have also omitted a detailed analysis of the devices that must and can be used, i.e. heat pumps (when receiving heat from the store), heat exchangers, pumps driving the flow, heat transfer from turbines to the store and others. In addition, we did not take into account issues such as costs and risk, as they were repeatedly presented and discussed in the literature. It is obvious that prices fluctuate over time and the quality of new installations improves, as does the safety of their operation. Moreover, along with the gradual depletion of the existing fuels, their prices rise, and the harmfulness associated with their use becomes increasingly onerous. As a result, energy costs must increase. If, as we have tried to show, there is no other 
reasonable and effective choice than NP, then a certain threat will have to be accepted as a result of logical analysis, devoid of unjustified fear, but based on thorough knowledge. One of the caveats that arises when discussing the use of a nuclear power plant is the scarcity of ${ }^{235} \mathrm{U}$. An approximate analysis shows that it should be enough for at least several dozen years. It is also possible to produce new fuels: ${ }^{239} \mathrm{Pu}$ from ${ }^{238} \mathrm{U}$ and ${ }^{233} \mathrm{U}$ from ${ }^{232} \mathrm{Th}$, and the resources (natural uranium and thorium) are many times greater than that of ${ }^{235} \mathrm{U}$. Both technologies have been developed and improved for many years. Examples of the practical production of these new fission nuclides can be found in nuclear countries, i.e. USA, Russia, China, India and others. In France, ${ }^{239} \mathrm{Pu}$ is already used as part of the reactor fuel, while India plans its nuclear power based on the fuel cycle of ${ }^{232} \mathrm{Th}$ and ${ }^{233} \mathrm{U}$.

Given that the earliest commissioning of the NuScale reactor may take place in the late 2030s, it is worth starting preparatory work, in particular by educating teachers at all levels and sending talented graduates and/or students for research and industrial internships to the company that will supply the reactor. The purpose of the latter would be to jointly adapt the reactor to work in a combined heat and power plant system. An important feature of the reactor is the ability to gradually start up 12 or 10 modules to "smooth" the financial burden until the power plant reaches full power. A high level of energy self-sufficiency of the city, low transmission losses from domestic electricity generation centres, stability of the reactor load and negligible air pollution would be extremely beneficial in this solution.

\section{References}

Assumptions for the Plan of Supplying Heat, Electricity and Gas to the Municipality of Cracow. Update. (in Polish: Założenia do planu zaopatrzenia gminy miejskiej Kraków w ciepło, energię elektryczną, paliwa gazowe. Aktualizacja), no. CXIX/1870/14, pp. 36-37, October 2014. Available:

https://www.bip.krakow.pl/?dok_id=167\&sub_dok_id=167\&sub=uchwala\&query=id\%3D20499\%26typ\%3Du

Power demand of the Country Energy System, (In Polish: Praca KSE - Zapotrzebowanie mocy KSE), PSE Polskie Sieci Energetyczne 2020, Available: https://www.pse.pl/obszary-dzialalnosci/krajowy-system-elektroenergetyczny/zapotrzebowanie-kse

Zangheri P., Armani R., Pietrobon M. Pagliano L., Boneta F., Müller A. Heating and cooling energy demand and loads for building types in different countries of the EU, no. D2.3 of WP2 of the Entranze Project, March 2014,

Available: https://www.entranze.eu/files/downloads/D2_3/Heating_and_cooling_energy_demand_and_loads_for_building_types_in_different_countries_of_the_

Energa RES. Units (In Polish: Energia OZE. Obiekty): Czernikowo, 2015. Available: https://energa-oze.pl/obiekty/farmy-fotowoltaiczne/19957/czernikowo

Rodziewicz T., Zaremba A., Wacławek M. Technical and Economic Aspects of Photovoltaic Conversion of Southern Poland, Ecol. Chem. Eng. vol. 21 no 2, pps.337-351, 2014

Lund PD., Lindgren J., Mikkola J. , Salpakari J. Review ofenergy system flexibility measures to enable high levels of variable renewable electricity. Renew. Sust. Energ. Rev. Volume 45. P. 785-807. ISSN 1364-0321(printed). DOI: 10.1016/j.rser.2015.01.057, 2015,

Available: https://aaltodoc.aalto.fi/bitstream/handle/123456789/26558/A1_lund_peter_d_2015.pdf

Land Cover and Ventilation Atlas of Cracow, in the report of the project Integrated monitoring system of spatial data to improve air quality in Kraków noPL030011, January 2016, Available: https://www.researchgate.net/publication/320735765

Jaskólski M., Reński A. Minkiewicz T. Thermodynamic and economic analysis of nuclear power unit operating in partial cogeneration mode to produce electricity and district heat, Energy, vol. 141 no. 20, pp. 2470-2483, 15 December 2017

Available:: https://www.sciencedirect.com/science/article/abs/pii/S0360544217307120

U.S. Nuclear Regulatory Commission (NRC), Application Documents for the NuScale Design, 2019, Available: https://www.nrc.gov/reactors/newreactors/design-cert/nuscale/documents.html

Coleman J., Bragg-Sitton S., Dufek E., Johnson S., Rhodes J., Davidson T., Webber ME. An Evaluation of Energy Storage Options for Nuclear Power, INL/EXT17-42420, INL Report, Idaho Falls, June 2017, Available:

https://inis.iaea.org/collection/NCLCollectionStore/_Public/48/074/48074824.pdf?r=1\&r=1

Novo AV., Rodriguez Bayón J., Castro-Fresno D., Rodriguez-Hernandez J. Review of seasonal heat storage in large basins: Water tanks and gravel-water pits, Appl. Energy vol. 87, pp. 390-397, February 2010

\section{Figures}




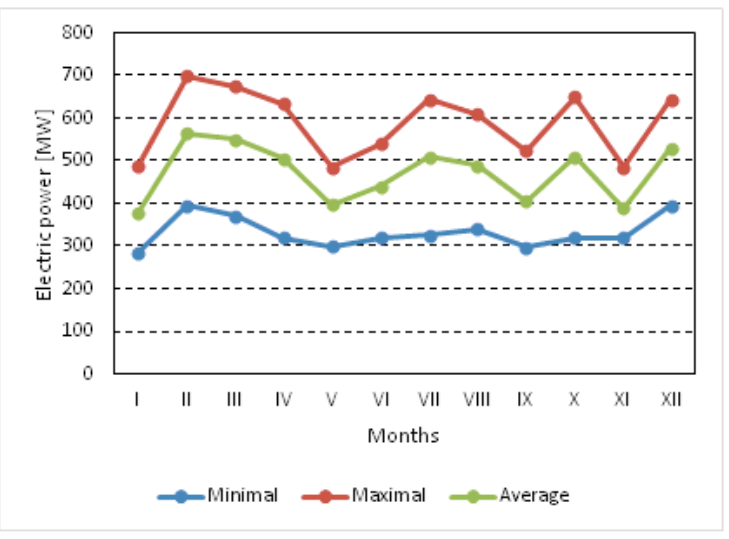

\section{Figure 1}

Characteristic monthly values of electricity demand in Kraków (based on data from October 1, 2018 to September 30, 2019)

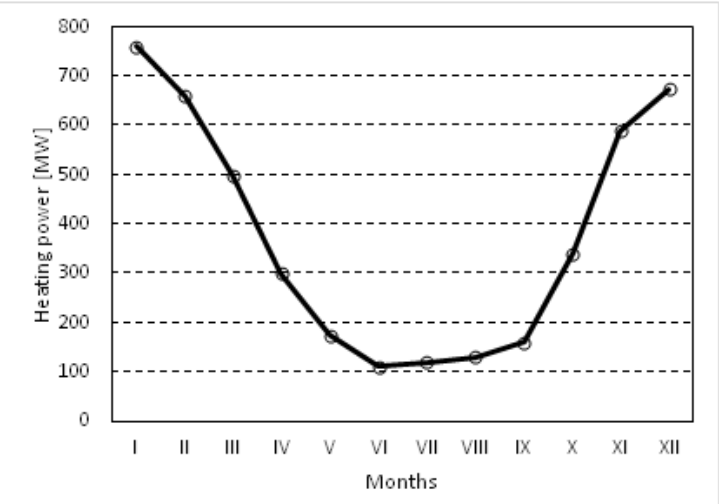

\section{Figure 2}

Characteristic average monthly values of heat power demand in Kraków - PZ

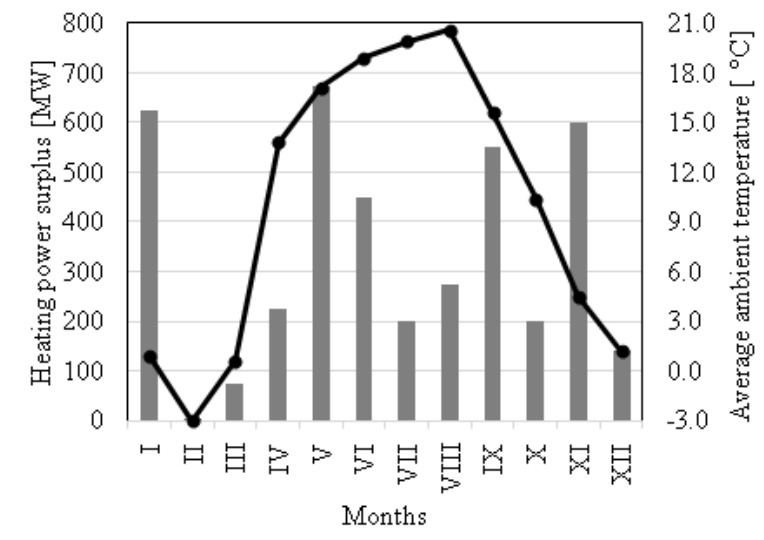

Heating power surplus $\rightarrow$ Average ambient tempereature

\section{Figure 3}

Please see the Manuscript file for the complete figure caption. 


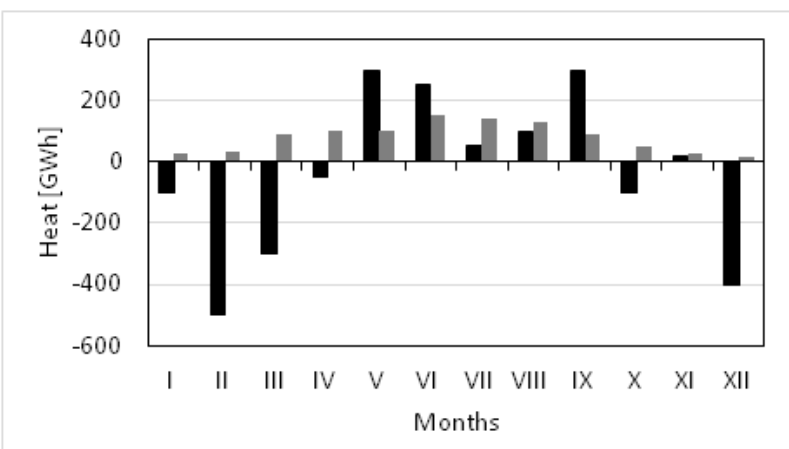

- Heat surplus from SMR Heat from solar collectors

\section{Figure 4}

Surplus heat from the reactor (SMR) reduced by the monthly heat demand, i.e. the amount of heat stored in the reservoir to cover the demand for the following months. Heat from solar collectors is presented separately.

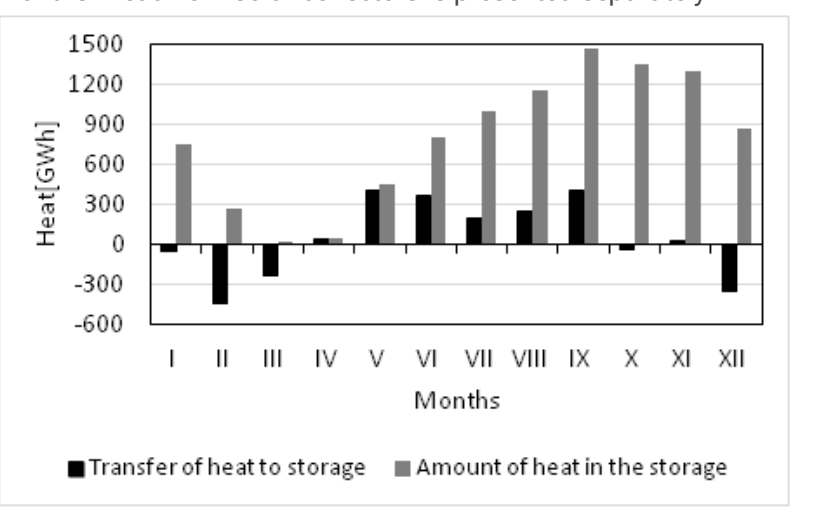

\section{Figure 5}

Resulting monthly heat transfer to the tank and the heat content of the tank, after taking into account the $5 \%$ content loss/month.

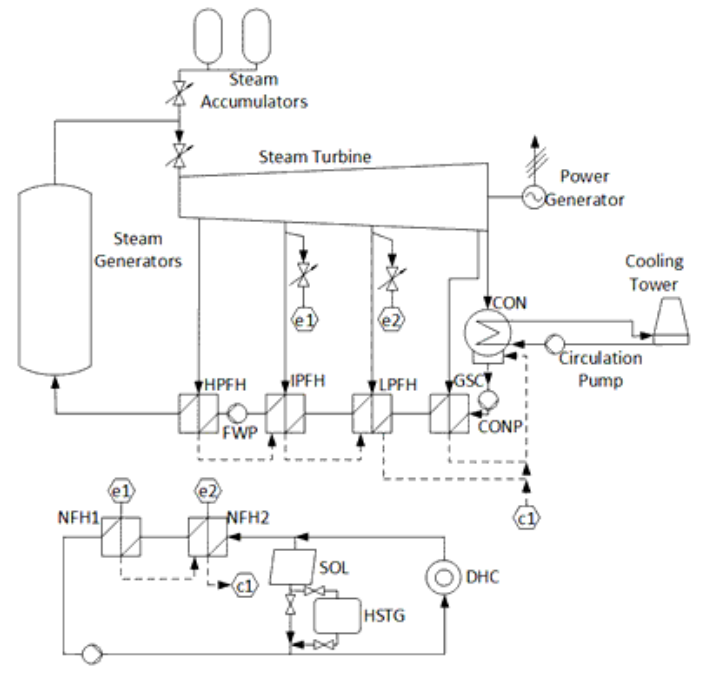

\section{Figure 6}

A simplified schematic diagram of a NuScale turbine adapted to cogeneration with steam accumulators, own illustration based on [8]. Note: HPFH, IPFH, LPFH - respectively: high pressure, intermediate, low pressure feed water heaters, GSC - gland steam condenser, CON - condenser, CONP - condensate pump, DHC district heat consumers, NFH1, NFH2 - heating networks, FWP - feed water pump, SOL - solar collectors, HSTG - low-temperature heat storage 


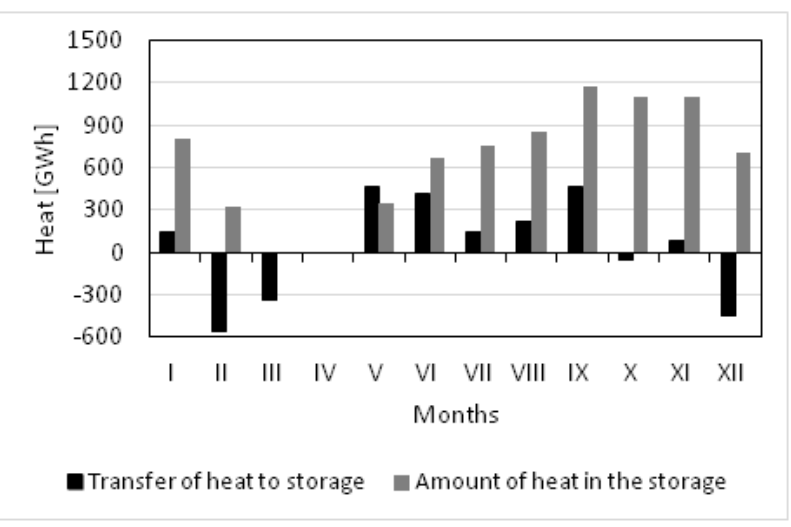

Figure 7

Resulting monthly heat transfer to the storage and the heat content of the storage, after taking into account the $5 \%$ content loss/month, for the $77 \mathrm{MWe}$ NuScale reactor version.

\section{Supplementary Files}

This is a list of supplementary files associated with this preprint. Click to download.

- DataAvailabilityStatement.docx 